\title{
Achieving the Recommended Endotracheal Tube Cuff Pressure: A Randomized Control Study Comparing Loss of Resistance Syringe to Pilot Balloon Palpation
}

\author{
Fred Bulamba, ${ }^{1}$ Andrew Kintu, ${ }^{2}$ Nodreen Ayupo, ${ }^{2}$ Charles Kojjo, ${ }^{2}$ Lameck Ssemogerere, ${ }^{2}$ \\ Agnes Wabule, ${ }^{2}$ and Arthur Kwizera ${ }^{2}$ \\ ${ }^{1}$ Department of Anaesthesia and Critical Care, Faculty of Health Sciences, Busitema University, Mbale, Uganda \\ ${ }^{2}$ Department of Anaesthesia and Critical Care, College of Health Sciences, Makerere University, Kampala, Uganda \\ Correspondence should be addressed to Fred Bulamba; fredflybulamba@gmail.com
}

Received 27 June 2017; Accepted 24 October 2017; Published 31 December 2017

Academic Editor: Ferenc Petak

Copyright (c) 2017 Fred Bulamba et al. This is an open access article distributed under the Creative Commons Attribution License, which permits unrestricted use, distribution, and reproduction in any medium, provided the original work is properly cited.

\begin{abstract}
Background. Both under- and overinflation of endotracheal tube cuffs can result in significant harm to the patient. The optimal technique for establishing and maintaining safe cuff pressures $\left(20-30 \mathrm{cmH}_{2} \mathrm{O}\right)$ is the cuff pressure manometer, but this is not widely available, especially in resource-limited settings where its use is limited by cost of acquisition and maintenance. Therefore, anesthesia providers commonly rely on subjective methods to estimate safe endotracheal cuff pressure. This study set out to determine the efficacy of the loss of resistance syringe method at estimating endotracheal cuff pressures. Methods. This was a randomized clinical trial. We enrolled adult patients scheduled to undergo general anesthesia for elective surgery at Mulago Hospital, Uganda. Study participants were randomized to have their endotracheal cuff pressures estimated by either loss of resistance syringe or pilot balloon palpation. The pressures measured were recorded. Results. One hundred seventy-eight patients were analyzed. 66.3\% (59/89) of patients in the loss of resistance group had cuff pressures in the recommended range compared with 22.5\% (20/89) from the pilot balloon palpation method. This was statistically significant. Conclusion. The loss of resistance syringe method was superior to pilot balloon palpation at administering pressures in the recommended range. This method provides a viable option to cuff inflation.
\end{abstract}

\section{Background}

High-volume low-pressure cuffed endotracheal tubes (ETT) are the standard of airway protection. However, they have potential complications [1-3]. Underinflation increases the risk of air leakage and aspiration of gastric and oral pharyngeal secretions $[4,5]$. Cuff pressures less than $20 \mathrm{cmH}_{2} \mathrm{O}$ have been shown to predispose to aspiration which is still a major cause of morbidity, mortality, length of stay, and cost of hospital care as revealed by the NAP4 UK study. In this cohort, aspiration had the second highest incidence of primary airway-related serious events [6].

On the other hand, overinflation may cause catastrophic complications. It has been demonstrated that, beyond $50 \mathrm{cmH}_{2} \mathrm{O}$, there is total obstruction to blood flow to the tracheal tissues. This has been shown to cause severe tracheal lesions and morbidity [7, 8]. However, less serious complications like dysphagia, hoarseness, and sore throat are more prevalent [9-11]. There are a number of strategies that have been developed to decrease the risk of aspiration, but the most important of all is continuous control of cuff pressures.

To achieve the optimal ETT cuff pressure of $20-30 \mathrm{cmH}_{2} \mathrm{O}$ [3, 8, 12-14], ETT cuffs should be inflated with a cuff manometer $[15,16]$. However, these are prohibitively expensive to acquire and maintain in many operating theaters, and as such, many anesthesia providers resort to subjective methods like pilot balloon palpation (PBP) which is ineffective [1, 2, 16-20]. Alternative, cheaper methods like the minimum leak test that require no special equipment have produced inconsistent results.

A newer method, the passive release technique, although with limitations, has been shown to estimate cuff pressures better [21-24]. This method has been achieved with a modified 
epidural pulsator syringe $[13,18]$, a $20 \mathrm{ml}$ disposable syringe, and more recently, a loss of resistance (LOR) syringe [21, 23, 24]. Compared with the cuff manometer, it would be cheaper to acquire and maintain a loss of resistance syringe especially in low-resource settings.

Our study set out to investigate the efficacy of the loss of resistance syringe in a surgical population under general anesthesia. ETT cuff pressures would be measured with a cuff manometer following estimation by either the PBP method or the LOR method. Our secondary objective was to determine the incidence of postextubation airway complaints in patients who had cuff pressures adjusted to $20-30 \mathrm{cmH}_{2} \mathrm{O}$ range or $31-40 \mathrm{cmH}_{2} \mathrm{O}$ range.

\section{Materials and Methods}

2.1. Study Design and Setting. This single-blinded, parallelgroup, randomized control study was performed at Mulago National Referral Hospital, Uganda. The hospital has a bed capacity of 1500 inpatient beds, 16 operating rooms, and a mean daily output of 90 surgical operations. Anesthesia services are provided by different levels of providers including physician anesthetists (anesthesiologists), residents, and nonphysician anesthetists (anesthetic officers and anesthetic officer students). In the early years of training, all trainees provide anesthesia under direct supervision. In the later years, however, they can administer anesthesia either independently or under remote supervision.

2.2. Study Population. We included ASA class I to III adult patients scheduled to receive general anesthesia with endotracheal intubation for elective surgical operation. All patients with any of the following conditions were excluded: known or anticipated laryngeal tracheal abnormalities or airway trauma, preexisting airway symptoms, laparoscopic and maxillofacial surgery patients, and those expected to remain intubated beyond the operative room period.

2.3. Randomization, Blinding, and Enrollment. After screening, participants were allocated to either the PBP or the LOR group using block randomization, achieving a $1: 1$ allocation ratio. The allocation sequence was generated by an Internet-based application with the following input: nine sets of unsorted sequences, each containing twenty unique allocation numbers (1-20). Numbers 1-10 were labeled LOR, and numbers 11-20 were labeled PBP. The allocation sequence was concealed from the investigator by inserting it into opaque envelopes (according to the clocks) until the time of the intervention.

At the time of the intervention, the study investigator retrieved the next available envelope, which indicated the intervention group, from the next available block envelope and handed it to the research assistant. The patient was the only person blinded to the intervention group.

The anesthesia providers were either physician anesthetists (anesthesiologists or residents) or nonphysicians (anesthetic officer or anesthetic officer student). Students were under the supervision of a senior anesthetic officer or an anesthesiologist.
2.4. Sample Size. To detect a $15 \%$ difference between PBP and LOR groups, it was calculated that at least 172 patients would be required to be $80 \%$ certain that the limits of a $95 \%$, two-sided interval included the difference.

2.5. Intervention and Anesthetic Technique. Every patient was wheeled into the operating theater and transferred to the operating table. Basic routine monitors were attached as per hospital standards. A wide-bore intravenous cannula (16- or $18-\mathrm{G}$ ) was placed for administration of drugs and fluids.

The patient was then preoxygenated with $100 \%$ oxygen and general anesthesia induced with a combination of drugs selected by the anesthesia care provider. These included an intravenous induction agent, an opioid, and a muscle relaxant. All patients received either suxamethonium $(2 \mathrm{mg} / \mathrm{kg}, \max$ $100 \mathrm{mg}$ to aid laryngoscopy) or cisatracurium $(0.15 \mathrm{mg} / \mathrm{kg}$ at for prolonged muscle relaxation) and were given optimal time before intubation. Using a laryngoscope, tracheal intubation was performed, ETT position confirmed, and secured with tape within $2 \mathrm{~min}$. The size of ETT (POLYMED Medicure, India) was selected by the anesthesia care provider. With the patient's head in a neutral position, the anesthesia care provider inflated the ETT cuff with air using a $10 \mathrm{ml}$ syringe (BD Discardit II). A research assistant (different from the anesthesia care provider) read out the patient's group, and one of the following procedures was followed.

PBP group (active comparator): in this group, the anesthesia care provider was asked to reduce or increase the pressure in the ETT cuff by inflating with air or deflating the pilot balloon using a $10 \mathrm{ml}$ syringe (BD Discardit II) while simultaneously palpating the pilot balloon until a point he or she felt was appropriate for the patient. When this point was reached, the $10 \mathrm{ml}$ syringe was then detached from the pilot balloon, and a cuff manometer (VBM, Medicintechnik Germany. Accuracy $-2 \mathrm{cmH}_{2} \mathrm{O}$ ) was attached. The pressure reading of the VBM was recorded by the research assistant.

LOR group (experimental): in this group, the research assistant attached a $7 \mathrm{ml}$ plastic, luer slip loss of resistance syringe (BD Epilor, USA) containing air onto the pilot balloon. The cuff was then briefly overinflated through the pilot balloon, and the loss of resistance syringe plunger was allowed to passively draw back until it ceased. This point was observed by the research assistant and witnessed by the anesthesia care provider. The loss of resistance syringe was then detached, the VBM manometer was attached, and the pressure reading was recorded.

Cuff pressure adjustment: in both arms, very high and very low pressures were adjusted as per the recommendation by the ethics committee. In case of a very low pressure reading (below $20 \mathrm{cmH}_{2} \mathrm{O}$ ), the ETT cuff pressure would be adjusted to $24 \mathrm{cmH}_{2} \mathrm{O}$ using the manometer. On the other hand, high cuff pressures beyond $50 \mathrm{cmH}_{2} \mathrm{O}$ were reduced to $40 \mathrm{cmH}_{2} \mathrm{O}$.

Also, at the end of the pressure measurement in both groups, the manometer was detached, breathing circuit was 


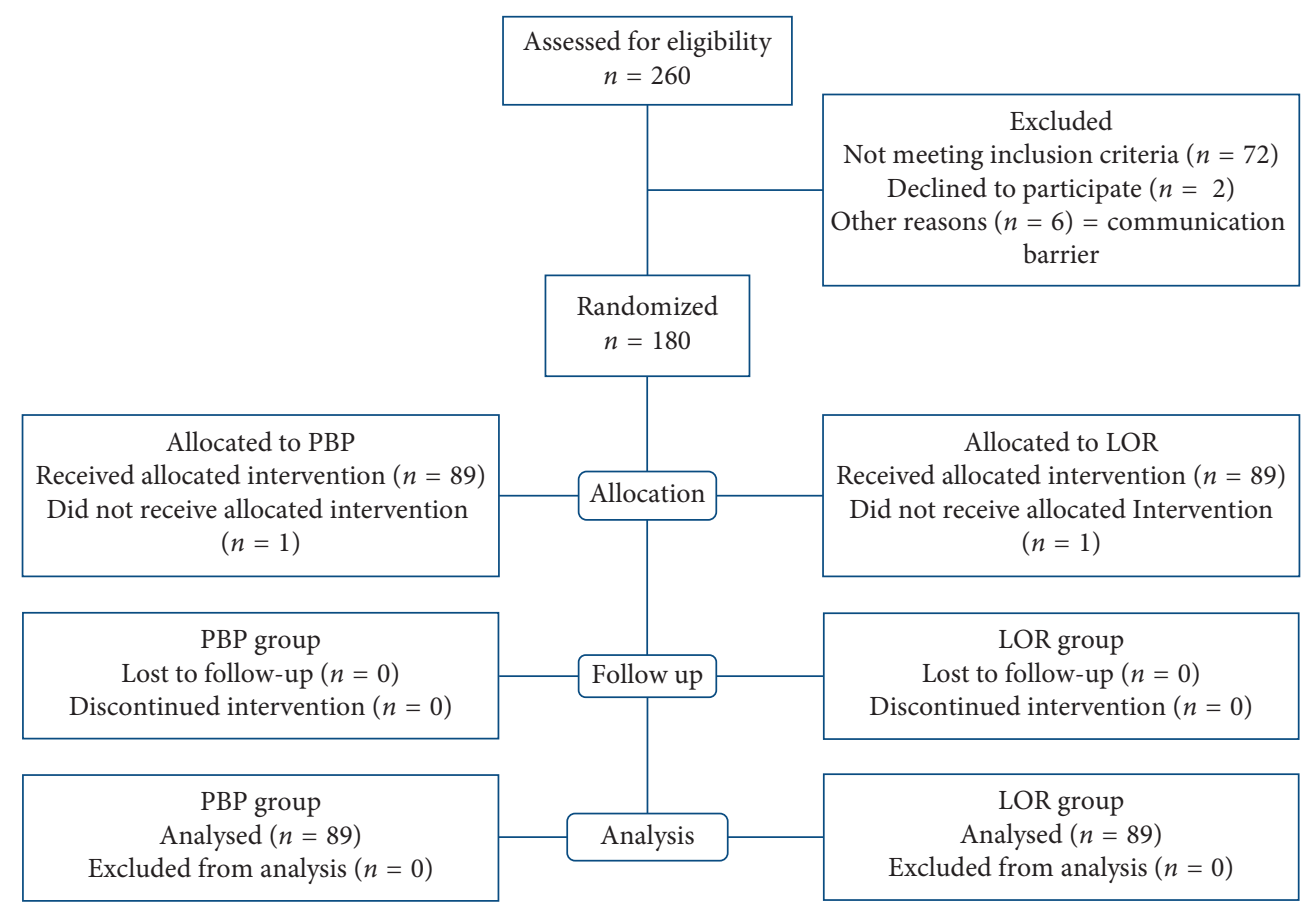

FIgURE 1: A CONSORT flow diagram of study patients. LOR = loss of resistance syringe method; $\mathrm{PBP}=$ pilot balloon palpation method.

attached to the ETT, and ventilation was started. The patient was maintained on isoflurane (1-1.8\%) mixed with $100 \%$ oxygen flowing at $2 \mathrm{~L} / \mathrm{min}$. Anesthesia continued without further adjustment of ETT cuff pressure until the end of the case. Nitrous oxide and medical air were not used as these agents are unavailable at this hospital. All patients who received nondepolarizing muscle relaxants were reversed with neostigmine $0.03 \mathrm{mg} / \mathrm{kg}$ and atropine $0.01 \mathrm{mg} / \mathrm{kg}$ at the end of surgery.

2.6. Primary Outcome. Cuff pressure reading of the VBM manometer was recorded by the research assistant. The individual anesthesia care providers participated more than once during the study period of seven months.

2.7. Secondary Outcome. The patients were followed up and interviewed only once at 24 hours after intubation for presence of cough, sore throat, dysphagia, and/or dysphonia. Only two of the four research assistants reviewed the patients postoperatively, and these were blinded to the intervention arm. This outcome was compared between patients with cuff pressures from 20 to $30 \mathrm{cmH}_{2} \mathrm{O}$ range and those from 31 to $40 \mathrm{cmH}_{2} \mathrm{O}$ following the initial correction of cuff pressures.

2.8. Data Management. All data were double entered into EpiData version 3.1 software (The EpiData Association, Odense, Denmark), with range, consistency, and validation checks embedded to aid data cleaning. The data were exported to and analyzed using STATA software version 12 (StataCorp Inc., Texas, USA).

Categorical data are presented in tabular, graphical, and text forms and categorized into PBP and LOR groups. The chi-square test was used for categorical data. Continuous data are presented as the mean with standard deviation and were compared between the groups using the $t$-test to detect any significant statistical differences.

The magnitude of effect on the primary outcome was computed for $95 \%$ CI using the $t$-test for difference in group means. An intention-to-treat analysis method was used, and the main outcome of interest was the proportion of cuff pressures in the range $20-30 \mathrm{~cm} \mathrm{H}_{2} \mathrm{O}$ in each group.

For the secondary outcome, incidence of complaints was calculated for those with cuff pressures from 20 to $30 \mathrm{cmH}_{2} \mathrm{O}$ range and those from 31 to $40 \mathrm{cmH}_{2} \mathrm{O}$.

2.9. Data Safety Management Board. The Data Safety Management Board (DSMB) comprised an anesthesiologist, a statistician, and a member of the SOMREC IRB who would be informed of any adverse event. The study would be discontinued if $5 \%$ of study subjects in one study group experienced an adverse event associated with the study interventions as determined by the DSMB, or if a $p$ value of $<0.001$ was obtained on an interim analysis performed halfway through patient accrual. None of these was met at interim analysis.

2.10. Ethical Considerations. The study was approved by the School of Medicine Research and Ethics Committee, Makerere University, and registered with http://www.clinicaltrials.gov (NCT02294422). All patients provided informed, written consent before the start of surgery.

\section{Results}

3.1. Baseline Characteristics. A total of 178 patients were enrolled from August 2014 to February 2015 with an equal 
TABLE 1: Baseline characteristics of patients.

\begin{tabular}{|c|c|c|c|c|}
\hline Variable & Pilot balloon palpation $(n=89)$ & Loss of resistance $(n=89)$ & Total $N=178$ & $p$ value \\
\hline \multicolumn{5}{|l|}{ Age group (years) } \\
\hline Mean (sd, min-max) & $42.3(15.6,19-89)$ & $42.6(15.2,18-78)$ & - & 0.19 \\
\hline \multicolumn{5}{|l|}{$\operatorname{Sex}, n(\%)$} \\
\hline Female & $62(69.7)$ & $74(83.1)$ & $136(76.4)$ & 0.034 \\
\hline Male & $27(30.3)$ & $15(16.9)$ & $42(23.6)$ & - \\
\hline \multicolumn{5}{|l|}{ ETT size in $m m, n(\%)$} \\
\hline 6.5 & $7(7.9)$ & $9(10.1)$ & $16(8.99)$ & - \\
\hline 7.0 & $38(42.7)$ & $34(38.2)$ & $72(40.45)$ & - \\
\hline 7.5 & $33(37)$ & $45(50.6)$ & $78(43.82)$ & 0.028 \\
\hline 8.0 & $6(6.7)$ & $1(1.1)$ & $7(3.93)$ & - \\
\hline 8.5 & $5(5.7)$ & $0(0)$ & $5(2.81)$ & - \\
\hline \multicolumn{5}{|c|}{ Duration of intubation in hrs, $n(\%)$} \\
\hline$\leq 1$ & $28(31.2)$ & $17(19.1)$ & $45(25.3)$ & - \\
\hline $1-2$ & $42(47.2)$ & $46(51.7)$ & $88(49.4)$ & - \\
\hline$>2$ & $19(21.6)$ & $26(29.2)$ & $45(25.3)$ & 0.14 \\
\hline \multicolumn{5}{|l|}{ Provider level, $n(\%)$} \\
\hline${ }^{*}$ Resident & $28(31.5)$ & $72(80.9)$ & $100(56.2)$ & - \\
\hline${ }^{* *} \mathrm{AO}$ & $51(57.3)$ & $10(11.2)$ & $61(34.3)$ & - \\
\hline AO students & $2(2.2)$ & $3(3.4)$ & $5(2.8)$ & - \\
\hline Anesthesiologist & $8(9.0)$ & $4(4.5)$ & $12(6.7)$ & - \\
\hline
\end{tabular}

${ }^{*}$ Anesthesiology resident, ${ }^{* *}$ anesthetic officer.

TABLE 2: ETT cuff pressure estimation by the PBP and LOR methods.

\begin{tabular}{lcccccc}
\hline & \multicolumn{5}{c}{ Cuff pressure ranges, $N(\%)$} \\
Method & $<20$ & $20-30$ & $31-40$ & $>40$ & Mean (sd) & Proportion adjusted \\
\hline PBP & 8 & 20 & 18 & 43 & $51(28.9)$ & $51(57.3)$ \\
LOR & 11 & 59 & 18 & 1 & $27(5.8)$ & $12(13.5)$ \\
\hline
\end{tabular}

All those $<20$ and $>40$ were adjusted by the manometer.

distribution between arms as shown in the CONSORT diagram in Figure 1.

The study comprised more female patients $(76.4 \%)$. In addition, most patients were below 50 years $(76.4 \%)$. The study groups were similar in relation to sex, age, and ETT size (Table 1).

3.2. ETT Cuff Pressures. Generally, the proportion of ETT cuffs inflated to the recommended pressure was less in the PBP group at 22.5\% (20/89) compared with the LOR group at $66.3 \%(59 / 89)$ with a statistically significant positive mean difference of 0.47 with $p$ value $<0.01(0.343-0.602)$. Also to note, most cuffs in the PBP group were inflated to a pressure that exceeded the recommended range in the PBP group, and $51 \%$ of the cuff pressures attained had to be adjusted compared with only $12 \%$ in the LOR group (Table 2 ).

The distribution of cuff pressures (unadjusted) achieved by the different care providers is shown in Figure 2. The difference in the number of intubations performed by the different level of providers is huge with anesthesia residents and anesthetic officers performing almost all intubation and initial cuff pressure estimations.
3.3. Postextubation Airway Symptoms. The total number of patients who experienced at least one postextubation airway symptom was 113 , accounting for $63.5 \%$ of all patients. The incidence of postextubation airway complaints after 24 hours was lower in patients with a cuff pressure adjusted to the 20-30 $\mathrm{cmH}_{2} \mathrm{O}$ range, $57.1 \%$ (56/98), compared with those whose cuff pressure was adjusted to the $30-40 \mathrm{~cm} \mathrm{H}_{2} \mathrm{O}$ range, $71.3 \%$ (57/80). This however was not statistically significant ( $p$ value 0.053 ) (Table 3$)$.

\section{Discussion}

4.1. Study Population. We conducted a single-blinded randomized control study to evaluate the LOR syringe method in accordance with the CONSORT guideline (CONSORT checklist provided as Supplementary Materials available here).

At the study hospital, there are more females undergoing elective surgery under general anesthesia compared with males. In addition, over $90 \%$ of anesthesia care at this hospital was provided by anesthetic officers and anesthesia residents during the study period. Anesthetic officers provide over $80 \%$ of anesthetics in Uganda. 


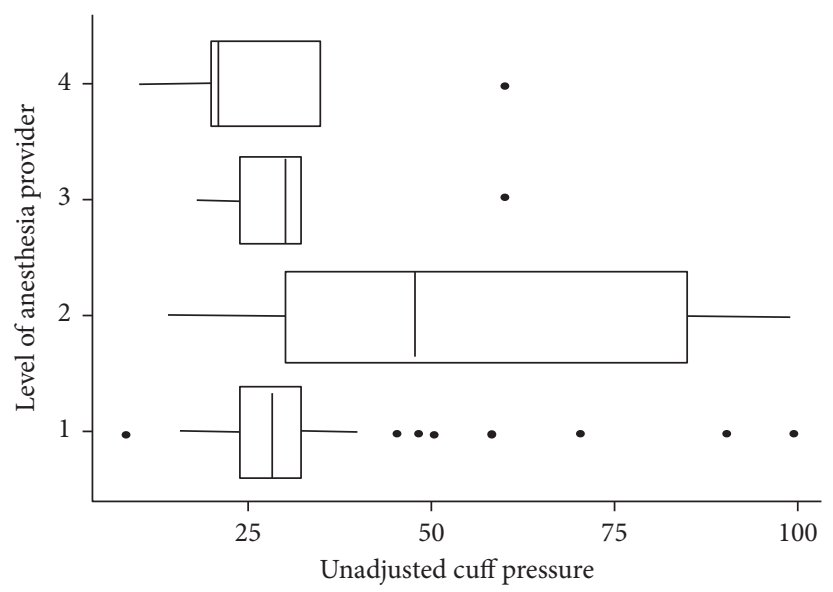

Figure 2: The distribution of cuff pressures achieved by the different levels of providers. 1: anesthesia resident; 2: anesthesia officer; 3: anesthesia officer student; 4: anesthesiologist.

TABLE 3: Incidence of postextubation airway complaints in the study population.

\begin{tabular}{|c|c|c|c|c|}
\hline Complaint, $n(\%)$ & All participants, $N=178$ & $20-30 \mathrm{cmH}_{2} \mathrm{O}, N=98$ & $31-40 \mathrm{cmH}_{2} \mathrm{O}, \mathrm{N}=80$ & $p$ value \\
\hline At least one & $113(63.5)$ & $56(57.1)$ & $57(71.2)$ & 0.052 \\
\hline None & $65(36.5)$ & $42(42.9)$ & $23(28.8)$ & - \\
\hline \multicolumn{5}{|l|}{ With cough } \\
\hline Yes & $45(25.3)$ & $17(17.3)$ & $28(35.0)$ & 0.07 \\
\hline No & $133(74.7)$ & $81(82.7)$ & $52(65.0)$ & - \\
\hline \multicolumn{5}{|l|}{ With dysphagia } \\
\hline Yes & $14(8.0)$ & $8(8.2)$ & $6(7.5)$ & 0.87 \\
\hline No & $164(92.0)$ & $90(91.8)$ & $74(92.5)$ & - \\
\hline \multicolumn{5}{|l|}{ With dysphonia } \\
\hline Yes & $16(9.0)$ & $14(14.3)$ & $2(2.5)$ & 0.029 \\
\hline No & $162(91.0)$ & $84(85.7)$ & $78(97.5)$ & - \\
\hline \multicolumn{5}{|l|}{ With sore throat } \\
\hline Yes & $89(50.0)$ & $42(42.9)$ & $47(58.7)$ & 0.035 \\
\hline No & $89(50.0)$ & $56(57.1)$ & $33(41.3)$ & - \\
\hline
\end{tabular}

4.2. ETT Cuff Pressure. The primary outcome of the study was to determine the proportion of cuff pressures in the optimal range from either group. The initial, unadjusted cuff pressures from either method were used for this outcome. When considering this primary outcome, the LOR syringe method had a significantly higher proportion compared to the PBP method. This adds to the growing evidence to support the use of the LOR syringe for ETT cuff pressure estimation. There are data regarding the use of the LOR syringe method for administering ETT cuff pressures [21, 23, 24], but studies on a perioperative population are scanty. In our study, $66.3 \%$ of ETT cuff pressures estimated by the LOR syringe method were in the optimal range. Kim and coworkers, who evaluated this method in the emergency department, found an even higher percentage of cuff pressures in the "normal range" $\left(22-32 \mathrm{cmH}_{2} \mathrm{O}\right)$ in their study. Another study, using nonhuman tracheal models and a wider range $\left(15-30 \mathrm{cmH}_{2} \mathrm{O}\right)$ as the optimal, had all cuff pressures within the optimal range [21]. It is however difficult to extrapolate these results to the human population since the risk of aspiration of gastric contents is zero while working with models when compared with patients.

There is a relatively small risk of getting ETT cuff pressures less than $30 \mathrm{cmH}_{2} \mathrm{O}$ with the use of the LOR syringe method $[23,24], 12.4 \%$ from the current study. Secondly, this method is still provider-dependent as they decide when plunger drawback has ceased. Precaution was taken to avoid premature detachment of the loss of resistance syringe in this study.

The PBP method, although commonly employed in operating rooms, has been repetitively shown to administer cuff pressures out of the optimal range $\left(20-30 \mathrm{cmH}_{2} \mathrm{O}\right)[2,3,25]$. Findings from this study were in agreement, with $25.3 \%$ of cuff pressures in the optimal range after estimation by the PBP method. It should however be noted that some of these studies have been carried out in different environments (emergency rooms) and on different kinds of patients (emergency patients) by providers of varying experience [2]. 
Another viable argument is to employ a more pragmatic solution to prevent overly high cuff pressures by inflating the cuff until no air leak is detected by auscultation. This method is cheap and reproducible and is likely to estimate cuff pressures around the normal range. Perhaps the LOR syringe method needs to be evaluated against the "no air leak on auscultation" method.

This study shows that the LOR syringe method is better at estimating cuff pressures in the optimal range when compared with the PBP method but still falls short in comparison to the cuff manometer. In low- and middleincome countries, the cost of acquiring (\$250-300) and maintaining a cuff manometer is still prohibitive.

4.3. Postextubation Airway Complaints. The secondary objective of the study evaluated airway complaints in those who had cuff pressure in the optimal range $\left(20-30 \mathrm{cmH}_{2} \mathrm{O}\right)$ and those above the range $\left(31-40 \mathrm{cmH}_{2} \mathrm{O}\right)$. The difference in the incidence of sore throat and dysphonia was statistically significant, while that for cough and dysphagia was not. The overall trend suggests an increase in the incidence of postextubation airway complaints in patients whose cuff pressures were corrected to $31-40 \mathrm{cmH}_{2} \mathrm{O}$ compared with those corrected to $20-30 \mathrm{cmH}_{2} \mathrm{O}$. This however was not statistically significant ( $p$ value 0.052 ).

Considering that this was a secondary outcome, it is possible that the sample size was small, hence leading to underestimation of the incidence of postextubation airway complaints between the groups. It is however possible that these results have a clinical significance.

The complaints sought in this study included sore throat, dysphagia, dysphonia, and cough. These were adopted from a review on postoperative airway problems [26] and were defined as follows: sore throat, continuous throat pain (which could be mild, moderate, or severe), dysphagia, uncoordinated swallowing or inability to swallow or eat, dysphonia, hoarseness or voice changes, and cough (identified by a discomforting, dry irritation in the upper airway leading to a cough). All these symptoms were of a new onset following extubation.

There is consensus that keeping ETT cuff pressures low decreases the incidence of postextubation airway complaints [11].

Previous studies have shown that the incidence of postextubation airway symptoms varies from $15 \%$ to $94 \%$ in various study populations $[7,9,11,27]$ and could be affected by the method of interview employed, such as the one used in our study (yes/no questions). This study was not powered to evaluate associated factors, but there are suggestions that the levels of anesthesia providers with varying skill set and technique at direct laryngoscopy may be associated with a high incidence of complications. However, this could be a site-specific outcome.

\section{Conclusion}

Although this was a single-blinded, single-centre study, results suggest that the LOR syringe method was superior to $\mathrm{PBP}$ at administering pressures in the optimal range.
The high incidence of postextubation airway complaints in this study is most likely a site-specific problem but one that other resource-limited settings might identify with.

We recommend the use of the cuff manometer whenever available and the LOR method as a viable option. Alternatively, cheaper, reproducible methods, like the minimum leak test that limit overly high cuff pressures should be sought and evaluated.

\section{Abbreviations \\ ETT: Endotracheal tube \\ PBP: Pilot balloon palpation \\ LOR: Loss of resistance \\ ASA: American Society of Anesthesiologists.}

\section{Data Access}

The datasets analyzed during the current study are available from the corresponding author on reasonable request.

\section{Ethical Approval}

The study was approved by Makerere University College of Health Sciences, School of Medicine Research Ethics Committee (SOMREC), The Secretariat Makerere University College of Health Sciences, Clinical Research Building, Research Co-ordination Office, P.O. Box 7072, Kampala, Uganda (Email: rresearch9@gmail.com; research@chs.mak. ac.ug). Informed consent was sought from all participants.

\section{Disclosure}

This work was presented (and later published) at the 28th European Society of Intensive Care Medicine congress, Berlin, Germany, 2015, as an abstract. The poster can be accessed by following the link: https://pdfs.semanticscholar. org/c12e/50b557dd519bbf80bd9fc60fb9fa2474ce27.pdf.

\section{Conflicts of Interest}

The authors declare that they have no conflicts of interest.

\section{Authors' Contributions}

Fred Bulamba, Andrew Kintu, Arthur Kwizera, and Arthur Kwizera were responsible for concept and design, interpretation of the data, and drafting of the manuscript. Charles Kojjo, Agnes Wabule, and Nodreen Ayupo were responsible for patient recruitment and data collection and analysis. All authors have read and approved the manuscript.

\section{Acknowledgments}

The authors wish to thank Ms. Martha Nakiranda, Bachelors of Arts in Education, Makerere University, Uganda, for her assistance in editing this manuscript. 


\section{Supplementary Materials}

CONSORT 2010 checklist. Endotracheal tube cuff pressure: a randomized control study comparing loss of resistance syringe to pilot balloon palpation. (Supplementary Materials)

\section{References}

[1] R. Fernandez, L. Blanch, J. Mancebo, N. Bonsoms, and A. Artigas, "Endotracheal tube cuff pressure assessment: pitfalls of finger estimation and need for objective measurement," Critical Care Medicine, vol. 18, no. 12, pp. 14231426, 1990.

[2] H. B. Ghafoui, H. Saeeidi, M. Yasinzadeh, S. Famouri, and E. Modirian, "Excessive endotracheal tube cuff pressure: is there any difference between emergency physicians and anesthesiologists?," Signa Vitae, vol. 7, no. 2, pp. 17-20, 2012.

[3] P. Sengupta, D. I. Sessler, P. Maglinger et al., "Endotracheal tube cuff pressure in three hospitals, and the volume required to produce an appropriate cuff pressure," $B M C$ Anesthesiology, vol. 4, no. 1, p. 8, 2004.

[4] J. Rello, R. Soñora, P. Jubert, A. Artigas, M. Rué, and J. Vallés, "Pneumonia in intubated patients: role of respiratory airway care," American Journal of Respiratory and Critical Care Medicine, vol. 154, no. 1, pp. 111-115, 1996.

[5] M. L. Sole, X. Su, S. Talbert et al., "Evaluation of an intervention to maintain endotracheal tube cuff pressure within therapeutic range," American Journal of Critical Care, vol. 20, no. 2, pp. 109-117, 2011.

[6] T. M. Cook, N. Woodall, and C. Frerk, "Major complications of airway management in the UK: results of the Fourth National Audit Project of the Royal College of Anaesthetists and the Difficult Airway Society. Part 1: anaesthesia," British Journal of Anaesthesia, vol. 106, no. 5, pp. 617-631, 2011.

[7] J. Liu, X. Zhang, W. Gong et al., "Correlations between controlled endotracheal tube cuff pressure and postprocedural complications: a multicenter study," Anesthesia and Analgesia, vol. 111, no. 5, pp. 1133-1137, 2010.

[8] R. D. Seegobin and G. L. van Hasselt, "Endotracheal cuff pressure and tracheal mucosal blood flow: endoscopic study of effects of four large volume cuffs," British Medical Journal, vol. 288, no. 6422, pp. 965-968, 1984.

[9] P. Biro, B. Seifert, and T. Pasch, "Complaints of sore throat after tracheal intubation: a prospective evaluation," European Journal of Anaesthesiology, vol. 22, no. 4, pp. 307-311, 1995.

[10] C. Stein, G. Berkowitz, and E. Kramer, "Assessment of safe endotracheal tube cuff pressures in emergency care - time for change?," South African Medical Journal, vol. 101, no. 3, p. 172, 2011.

[11] N. Suzuki, K. Kooguchi, T. Mizobe, M. Hirose, Y. Takano, and Y. Tanaka, "Postoperative hoarseness and sore throat after tracheal intubation: effect of a low intracuff pressure of endotracheal tube and the usefulness of cuff pressure indicator," Masui, vol. 48, no. 10, pp. 1091-1095, 1999.

[12] W. N. Bernhard, L. Yost, D. Joynes, S. Cothalis, and H. Turndorf, "Intracuff pressures in endotracheal and tracheostomy tubes. Related cuff physical characteristics," Chest, vol. 87, no. 6, pp. 720-725, 1985.

[13] N. Lomholt, "A device for measuring the lateral wall cuff pressure of endotracheal tubes," Acta Anaesthesiologica Scandinavica, vol. 36, no. 8, pp. 775-778, 1992.

[14] U. Nordin, "The trachea and cuff-induced tracheal injury: an experimental study on causative factors and prevention," Acta Oto-Laryngologica, vol. 345, pp. S1-S71, 1977.
[15] J. R. Bouvier, "Measuring tracheal tube cuff pressures-tool and technique," Heart and Lung, vol. 10, no. 4, pp. 686-690, 1981.

[16] R. J. Hoffman, V. Parwani, and I. H. Hahn, "Experienced emergency medicine physicians cannot safely inflate or estimate endotracheal tube cuff pressure using standard techniques," American Journal of Emergency Medicine, vol. 24, no. 2, pp. 139-143, 2006.

[17] V. Foroughi and R. Sripada, "Sensitivity of tactile examination of endotracheal tube intra-cuff pressure," Anesthesiology, vol. 87, no. 3, p. 965A, 1997.

[18] E. Resnikoff and A. J. Katz, "A modified epidural syringe as an endotracheal tube cuff pressure-controlling device," Anaesthesia and Analgesia, vol. 70, no. 2, pp. 208-211, 1990.

[19] S. Stewart, J. A. Secrest, B. R. Norwood, and R. Zachary, "A comparison of endotracheal tube cuff pressures using estimation techniques and direct intracuff measurement," American Journal of Nurse Anesthestists, vol. 71, no. 6, pp. 443-447, 2003.

[20] S. W. Wangaka, Estimation of endotracheal tube cuff pressures at Kenyatta National Hospital, University of Nairobi, Nairobi, Kenya, 2006.

[21] C. K. Cho, H. U. Kwon, M. J. Lee, S. S. Park, and W. J. Jeong, "Application of perifix (R) LOR (loss of resistance) syringe for obtaining adequate intracuff pressures of endotracheal tubes," Journal of Korean Society of Emergency Medicine, vol. 21, no. 2, pp. 175-183, 2010.

[22] H. Jin, G. Y. Tae, K. K. Won, J. Young, and K. K. Duk, "Usefulness of new technique using a disposable syringe for endotracheal tube cuff inflation," Korean Journal of Anesthesiology, vol. 56, no. 5, pp. 513-518, 2009.

[23] H. M. Kim, J. K. No, Y. S. Cho, and H. J. Kim, "Application of a loss of resistance syringe for obtaining the adequate cuff pressures of endotracheal intubated patients in an emergency department," Journal of the Korean Society of Emergency Medicine, vol. 23, no. 6, pp. 769-775, 2012.

[24] K. C. Park, Y. D. Sohn, and H. C. Ahn, "Effectiveness, preference and ease of passive release techniques using a syringe for endotracheal tube cuff inflation," Journal of the Korean Society of Emergency Medicine, vol. 21, no. 6, pp. 795-800, 2010.

[25] L. Gilliland, H. Perrie, and J. Scribante, "Endotracheal tube cuff pressures in adult patients undergoing general anaesthesia in two Johannesburg Academic Hospitals," Southern African Journal of Anaesthesia and Analgesia, vol. 21, no. 3, pp. 81-84, 2015.

[26] L. Zuccherelli, "Postoperative upper airway problems," Southern African Journal of Anaesthesia and Analgesia, vol. 9, no. 2, p. 5, 2003.

[27] M. H. Bennett, P. R. Isert, and R. G. Cumming, "Postoperative sore throat and hoarseness following tracheal intubation using air or saline to inflate the cuff-a randomized controlled trial," Anesthesia and Analgesia, vol. 28, no. 4, pp. 408-413, 2000. 


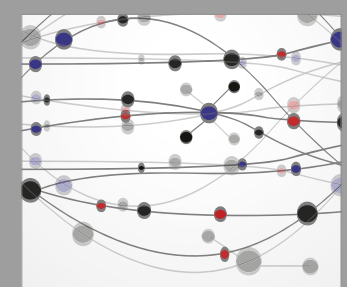

The Scientific World Journal
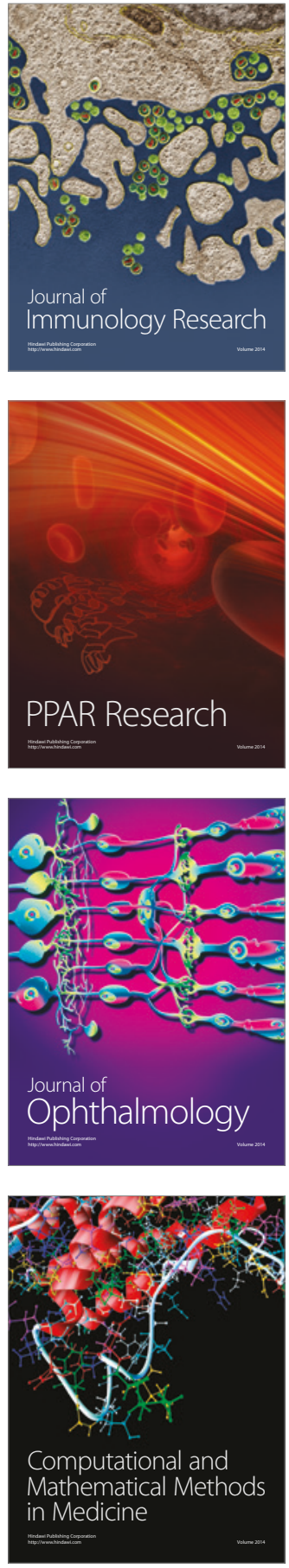

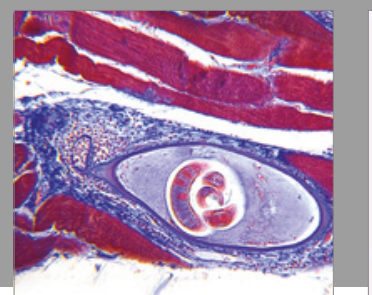

Gastroenterology Research and Practice
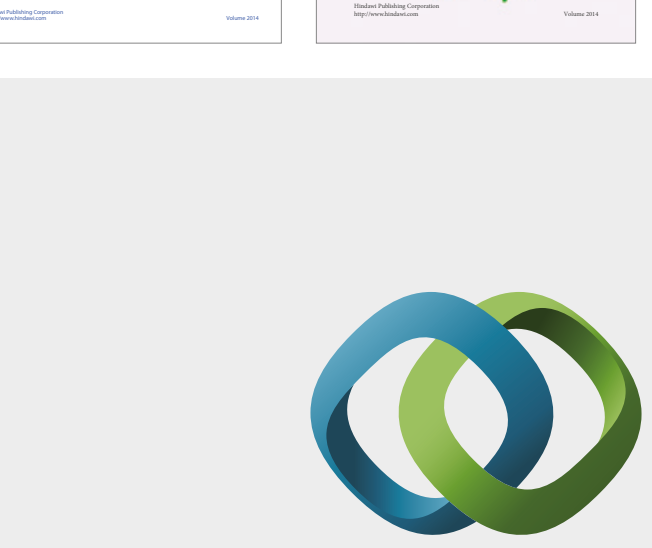

\section{Hindawi}

Submit your manuscripts at

https://www.hindawi.com
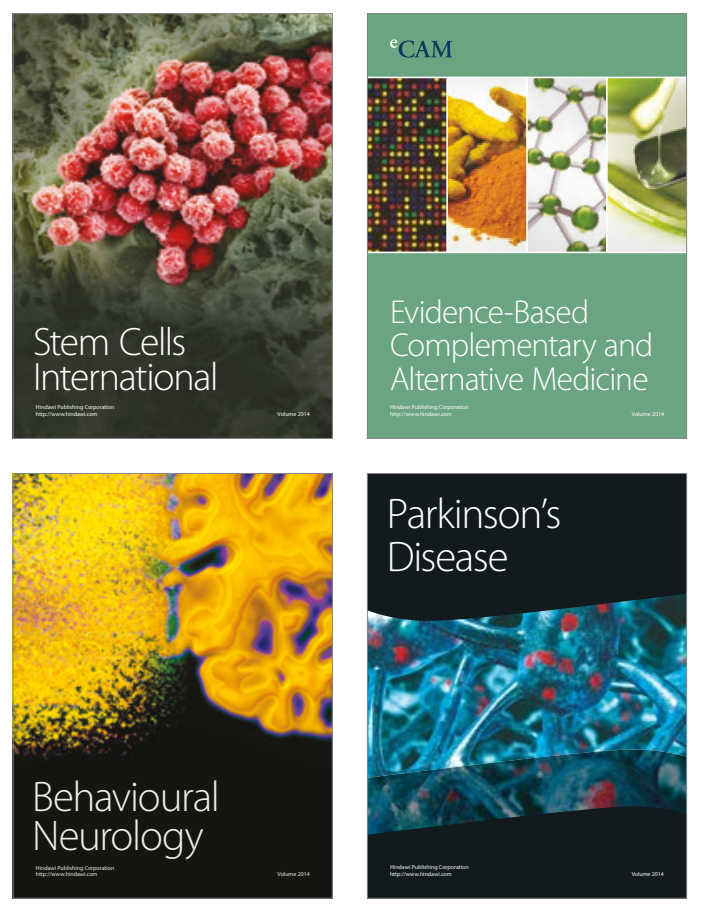
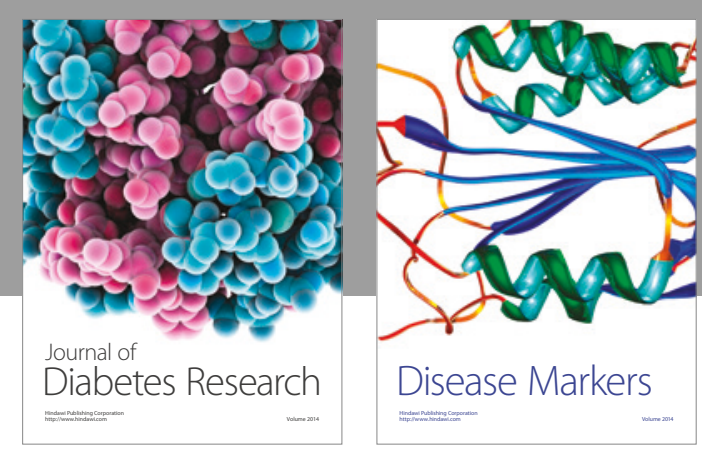

Disease Markers
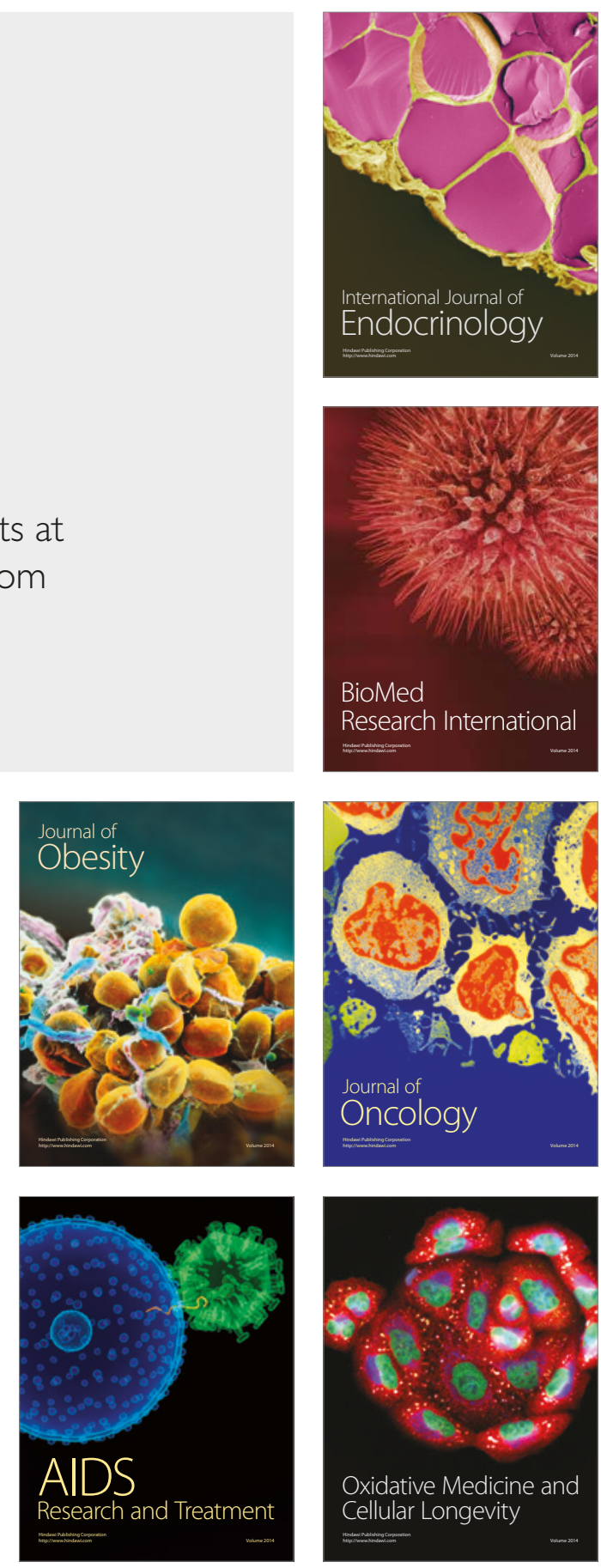